\title{
miR-I-3p suppresses the epithelial-mesenchymal transition property in renal cell cancer by downregulating Fibronectin I
}

This article was published in the following Dove Press journal: Cancer Management and Research

\author{
Jianghui Liu' ${ }^{1} *$ \\ Yingxiong Huang ${ }^{1} *$ \\ Quanyong Cheng',* \\ Jifei Wang' \\ Jidong Zuo' \\ Ying Liang ${ }^{2}$ \\ Gang Yuan'
}

'Department of Emergency and Internal Medicine, The First Affiliated Hospital of

Sun Yat-Sen University, Guangzhou 510080, People's Republic of China;

${ }^{2}$ Department of Nephrology, The Eighth People's Hospital of Guangzhou,

Guangdong 510060, People's Republic of China

*These authors contributed equally to this work
Correspondence: Gang Yuan Department of Emergency and Internal Medicine, The First Affiliated Hospital of Sun Yat-Sen University, \#58

Zhongshaner Road, Guangzhou 510080,

People's Republic of China

Tel +868 2087755766

Fax +868 2087755766

Email yuangang@mail.sysu.edu.cn

Ying Liang

Department of Nephrology, The Eighth People's Hospital of Guangzhou, \#627

Dongfengdong Road, Guangdong 510060,

People's Republic of China

$\mathrm{Tel}+8683838688$

$\mathrm{Fax}+8683838688$

Email gz8hliangying@yeah.net
Purpose: Renal cell cancer (RCC) is one of the primary causes of malignancy deaths all over the world. The most important cause of RCC-related mortality is metastasis. Epithelialmesenchymal transition (EMT) plays an important role in metastasis of malignant tumors including RCC. miR-1-3p is confirmed to be decreased in many types of cancer. Nevertheless, the function of miR-1-3p in RCC metastasis and EMT process was still unclear.

Materials and methods: In this study, information from clinical investigation, in vitro study, and in vivo study discovered miR-1-3p expression character and its status in RCC. The character of miR-1-3p in invasive and metastatic properties in vitro and in vivo was also inspected in RCC cells and xenograft tumor model, and expression levels of EMT markers were evaluated in RCC cells and tissues.

Results: miR-1-3p was proved to be decreased in RCC cell lines and tissues compared with normal renal cells and tissues. miR-1-3p expression level in RCC tissues was closely related with capsulation, lymph node metastasis, and vascular invasion. miR-1-3p was found to be able to block the EMT process in A498 and CAKI-1 RCC cells and tumors. Luciferase reporter assay and expression level rescue assays were employed to reveal that miR-1-3p inhibited the invasion and migration property of RCC cells by directly targeting Fibronectin 1. Upregulation of Fibronectin 1 partially reversed the suppressive effect of miR-1-3p on EMT process.

Conclusion: In brief, this study has verified that miR-1-3p blocked the EMT process of RCC cells by reducing Fibronectin 1 expression. miR-1-3p/Fibronectin 1 axis may be considered as a new target for drug development of RCC.

Keywords: renal cell carcinoma, microRNA-1-3p, Fibronectin 1, epithelial-to-mesenchymal transition, migration, invasion

\section{Introduction}

Renal cell cancer (RCC) is the most common type of human malignancies of the urological system. ${ }^{1}$ RCC treatment will fail if recurrence and metastasis occur after surgery or chemotherapy. ${ }^{2}$ Despite improvements in diagnosis and treatment strategies, the 5-year survival rate of patients with advanced renal cell carcinoma remains low. Therefore, the specific mechanism of recurrence and metastasis of renal cell carcinoma needs to be fully elucidated. ${ }^{3}$ The epithelial-to-mesenchymal transition process (EMT) is considered a pivotal procedure that occurs during metastasis process in various cancer includes RCC. ${ }^{4}$ EMT offers cancer cells with increased invasive and migratory capacity, and further empowering dissemination and metastasis. ${ }^{5}$ The EMT process of RCC cells is characterized by a series of 
phenotypic changes; including reprogramming process of polarized epithelial cells into spindle-shaped migratory cells similar to mesenchymal/myofibroblast cell, and breakdown of cell-to-cell or cell-to-extracellular matrix adherence. ${ }^{6}$ EMT is associated with complex gene reprogramming coordinated by EMT transcription factors such as SLUG. EMT is associated with complex gene reprogramming coordinated by EMT transcription factors such as Slug. ${ }^{7}$ These gene reprogramming are usually characterized by the downregulation of epithelial marker genes and the upregulation of mesenchymal marker genes. ${ }^{8}$ Actually, Slug is a member of the SNAIL family of transcriptional repressors, is known to play a critical role in the EMT process. ${ }^{9}$ E-cadherin, an important epithelial marker, is a transmembrane protein which connects epithelial cells together at adherens junctions. The dysfunction of E-cadherin is a remarkable sign of the beginning of EMT. ${ }^{10}$ Slug upregulation or E-cadherin dysfunction has commonly been associated with poor prognosis and short survival in RCC patients. ${ }^{11}$ However, there is a limited understanding of the inducing factors of EMT in RCC. MicroRNAs (miRNA/miR) are small noncoding RNA fragments that can regulate the expression of various proteins by binding to the $3^{\prime}$-untranslated regions (3'-UTR) of objective target mRNA. ${ }^{12}$ Moreover, miRNAs have been presented to play an essential role in migration property of various cancer cells, ${ }^{13}$ as either EMT process regulators. microRNA-1-3p (miR-1-3p) was found as a novel marker and plays as a tumor growth and migration suppressor in urinary system tumors such as bladder cancer ${ }^{14}$ and prostate cancer. ${ }^{15}$ Previous preliminary reports showed that miR-1, a homologous analog of mir-1-3p, may reflect RCC heterogeneity. ${ }^{16}$ Kawakami et $a 1,{ }^{17}$ speculated through preliminary in vitro experiments that mirR-1 might be related to apoptosis and cycle arrest of RCC. But whether miR-1-3p can take effect in the invasion and migration of RCC has not been illustrated comprehensively to date. Moreover, the mechanism of how miR$1-3 p$ affects RCC has not been investigated up to now in vitro or in vivo. As a result, in the current study, it was proved that the expression level of miR-1-3p in several RCC cell lines and clinical tissues was considerably lower than that in normal renal cell lines and tissues. Furthermore, it was confirmed that the lower expression level of miR-1-3p was significantly associated with numerous migration property of RCC. Additionally, upregulation of miR-1-3p expression in RCC cell lines may prevent cell migration and invasion via the EMT process.
Previous studies in various tumors have revealed that miR1 may play a role in the suppressive effects by directly inhibiting some targeted proteins, such as CCND $1,{ }^{18}$ CCND2, ${ }^{19,20}$ CDK4 $4{ }^{21}$ CDK6, ${ }^{22}$ CXCR $4,{ }^{23}$ Caprin $1,{ }^{24}$ CDK $9{ }^{25-27}$ and so on. In this study, we further explored the target of miR-1-3p in RCC. A further mechanistic study exposed that Fibronectin 1 was the direct target gene of miR-1-3p to influence EMT process of RCC cells in vitro and in vivo. Accordingly, miR-1-3p may suppress the migration property of RCC cells through Fibronectin 1-mediated EMT.

\section{Materials and methods Clinical samples}

The current retrospective study enrolled 58 patients diagnosed with primary RCC who underwent surgical resection in the First Affiliated Hospital of Sun Yat-Sen University from March 2011 to March 2014. The mean patient age was $43.22 \pm 6.25$ years (range 22-68 years). None of the patients had received any radiotherapy or chemotherapy. All patients were followed up every 2 months in the first 12 months after the operation, and every 6 months thereafter. Routine blood tests, recurrent lesions were confirmed by CT or/and MRI, or by biopsy. If there was RCC recurrence, patients were evaluated in the First Affiliated Hospital of Sun Yat-Sen University for treatment guidance based on the status of tumor and general condition of the patient. All clinical investigations were conducted according to the principles expressed in the Declaration of Helsinki. All paraffin-embedded and fresh tissues were obtained for research purposes with the consent of each patient. Written informed consent was obtained from all patients, and research protocols were approved by the Clinical Research Ethics Committees of the First Affiliated Hospital of Sun YatSen University. The Clinical Research Ethics Committees of the First Affiliated Hospital of Sun Yat-Sen University approved the protocol.

\section{RT-PCR assay and Western blot assay}

RT-PCR assay and Western blot assay were carried out with the methods reported in the literature. ${ }^{28}$ Total RNA was extracted using either an miRNeasy kit (Qiagen, Inc., Valencia, CA, USA) or TriReagent (Sigma-Aldrich; Merck KGaA, Darmstadt, Germany) at room temperature for 10 mins, according to the manufacturer's protocols, from tissue lysates or cell samples, followed by reverse transcription to 
cDNA with TaqMan ${ }^{\circledR}$ miRNA Reverse Transcription kit (Applied Biosystems; Thermo Fisher Scientific, Inc.) or tranScript first-strand cDNA Synthesis SuperMix kit (Qiagen, Inc.). Relative expression levels of miR-1-3p were determined using the TaqMan $^{\circledR}$ microRNA Assay (Applied Biosystems; Thermo Fisher Scientific, Inc.) protocol specific for miR-1-3p, and were normalized to that of internal control $\mathrm{U} 6$ by using the $2-\Delta \Delta \mathrm{Cq}$ method. Relative expression levels of Fibronectin 1 were determined using the Premix Ex Taq $^{\mathrm{TM}}$ kit (Qiagen GmbH, Hilden, Germany) with the following primers: Fibronectin 1 forward, 5'CTGGGCATGCACCCGCCTCA-3' and reverse, 5'-GTATCTGACATGGTACACAATTT-3'. The relative amount of mRNA was normalized by using $\beta$-actin. Experiments were repeated three times.

The protein contents of tissues or cell lysates were measured. A suitable amount of total protein of each sample was then separated by $10 \%$ SDS-PAGE. Following vertical electrophoretic separation, proteins were transferred to polyvinylidene fluoride membranes by wet transfer. Subsequently, PVDF membranes were blocked with 5\% fat-free milk for 60 mins at room temperature, and then incubated with rabbit anti-Fibronectin 1 antibodies, rabbit anti-E-cadherin antibodies, rabbit anti-Slug antibodies, and rabbit anti- $\beta$-actin antibody (all from Abcam, USA) at $4^{\circ} \mathrm{C}$ overnight. Membranes were washed three times in tris-buffered saline with Tween20 (TBST), and were then incubated with HRP-conjugated secondary antibody (Bio-Rad, Hercules, CA, USA) at room temperature for 60 mins. After washing again three times with TBST, exposure and development were performed and densities were measured. All experiments were performed in triplicate.

\section{Cell lines, cell culture, and cell transfection}

The immortalized human renal cell line $\mathrm{HK}-2^{29,30}$ and the RCC cell lines, OS-RC-2, ${ }^{31,32} \mathrm{CAKI}-1,{ }^{33} \mathrm{ACHN},{ }^{34} 769-\mathrm{P},{ }^{35}$ $\mathrm{A} 498^{36}$, and $786-\mathrm{O}^{37}$ were purchased from the American Type Culture Collection (Manassas, VA, USA). Cells were all maintained at $37^{\circ} \mathrm{C}$ and $5 \% \mathrm{CO}_{2}$ in 1,640 medium with $10 \%$ fetal bovine serum (FBS) (Life Technologies, Grand Island, NY, USA). Transfection was generally performed on cells grown to about $65 \%$ density. To increase intracellular expression of miR-1-3p or Fibronectin 1, oligonucleotides were designed and cloned into the plasmid vector. Cells were transiently transfected with the miR-1-3p plasmid or Mock Control miR plasmid (Ambion, Austin, TX, USA) according to the manufacturer's instructions. Cells stably overexpressing miR-1-3p were generated by lentiviral transfection with a vector expressing miR-1-3p or a miR-Mock Control (MC) vector according to the manufacturer's protocol (Lenti-miR ${ }^{\mathrm{TM}}$ microRNA precursor clones, SBI System Biosciences, Palo Alto, CA, USA). Successfully transfected cells were selected for 12 days with $0.5 \mu \mathrm{g} / \mathrm{mL}$ neomycin at $72 \mathrm{hrs}$ after infection, and transfection was confirmed by the expression of green fluorescence protein. $^{38}$ All constructs were verified by sequencing.

\section{Cell counting kit-8 (CCK-8) assay}

The proliferation ability of A498 or CAKI-1 cells was measured using a CCK-8 kit (Dojindo, Japan) ${ }^{39}$ according to the manufacturer's instructions. Briefly, A498 or CAKI-1 cells were seeded into 96 -well plates at a density of $1 \times 10^{4}$ cells/well and incubated for 24, 48, or 72 hrs. Subsequently, $10 \mu \mathrm{L}$ of CCK-8 reagent was added into the well and cultured for another $1 \mathrm{hr}$. Miniature microplate readers were used to determine the optical density (OD). ${ }^{40}$ All of the experiments were performed in triplicate.

\section{Wound healing assay}

Wound healing assay was carried out with the methods reported in the literature. ${ }^{41}$ A498 $\left(1 \times 10^{6}\right)$ or CAKI-1 $\left(1 \times 10^{6}\right)$ cells were plated into six-well plates and grew to $70 \%$ confluence. A constant wide wound was created using a sterile pipette tip on a monolayer cultured with A498 or CAKI-1 cells. At 48 hrs after migration of A498 or CAKI-1 cells, the average migrating distance to the scraped area was measured under an inverted microscope and photographed. ${ }^{42}$ Migration analyses were performed in triplicate.

\section{Matrigel-coated transwell assay}

Invasion ability was evaluated by Transwell assay using 12well Matrigel-coated Transwell chambers (BD Biosciences, MA, USA). ${ }^{43}$ Briefly, upper chambers coated with Matrigel were loaded with A498 or CAKI-1 cells suspended in serumfree 1640 medium, while lower chambers were loaded with medium with $10 \%$ FBS. A498 or CAKI-1 cells were allowed to invade through the filter for $48 \mathrm{hrs}$, and cells on the upper sides were carefully removed. Cells that invaded to the lower side were stained with $0.5 \%$ crystal violet and $4 \%$ paraformaldehyde at room temperature and the number of penetrating cells was calculated in three random fields per membrane under an inverted microscopy at $200 \times$ magnification. ${ }^{44}$ Invasion assays were performed in triplicate. 


\section{Target prediction and luciferase reporter assays}

The miRNA-targeted proteins were predicted using the miRanda, ${ }^{45}$ TargetScan ${ }^{46-48}$, and PicTar ${ }^{49,50}$ databases. A site-directed mutagenesis kit (Stratagene; Agilent Technologies, Inc., Santa Clara, CA, USA) was used to produce a mutant Fibronectin 1 3'UTR luciferase reporter vector (MUT-Fibronectin 1-3'UTR), according to the manufacturer's protocol. The luciferase reporter was composed containing regions of the Fibronectin 13 '-UTR with the indicated miR-1-3p target sites or mutant sites to determine whether Fibronectin 1 was a direct target of miR-1-3p. Cells were seeded in triplicate in six-well plates and allowed to settle for $12 \mathrm{hrs}$. Indicated plasmids and equal amounts of miR-1-3p or MC RNA were transfected into the cells (Life Technologies). At $24 \mathrm{hrs}$ after transfection, luciferase activity was measured using a Dual-Luciferase Reporter Assay system (Promega Corporation).

\section{Xenografted tumor model}

BALB/c mice (male, 16-20 g) were obtained from Vital River Laboratories (Beijing, China). All animal experiments were carried out according to the National Institutes of Health Guide for the Care and Use of Laboratory Animals. Experimental procedures were approved by the Institutional Animal Care and Use Committee (IACUC) of the First Affiliated Hospital of Sun Yat-Sen University. Animals were treated humanely for all experimental procedures. All animals were lawfully acquired and their retention and use were in compliance with federal, state, and local laws and regulations, and in accordance with the guidelines of the IACUC guide for care and use of laboratory animals. Immunodeficient mice were randomly divided into every group ( $\mathrm{n}=6$ per group). Aforementioned stably transfected cells $\left(1 \times 10^{6}\right)$ were injected subcutaneously into the dorsal left flank of nude mice. ${ }^{51}$ The transfected cells included A498 or CAKI-1 RCC cells stably expressing miR1-3p or Mock Control miR. Tumors were examined once every week, lengths (L) and widths (W) were measured, and tumor volumes were calculated using the equation $\left(\mathrm{L} \times \mathrm{W}^{2}\right) / 2$. On day 28 , animals were sacrificed, and tumors were harvested and weighed; tissues were used for Fibronectin 1, E-cadherin, Slug and $\beta$-actin protein quantification.

\section{Statistical analysis}

Statistical analyses were performed using SPSS 15.0 (SPSS, Inc., Chicago, IL, USA). The data were presented as the mean \pm SD (standard deviation). The two-tailed Student's $t$-test and
ANOVA test were implemented to determine differences. $P<0.01$ was considered to indicate a statistically significant difference.

\section{Results}

\section{miR-I-3p was downregulated in RCC cell lines and tissues}

RT-PCR assay was performed to evaluate the expression levels of miR-1-3p in RCC cell lines OS-RC-2, CAKI-1, ACHN, 769-P, A498, and 786-O. miR-1-3p expression was found to be significantly reduced in RCC cell lines, compared with the immortalized human renal cell line HK-2 $(P<0.01$, Figure 1A). The association between miR-1-3p and the clinicopathological parameters of patients with RCC was analyzed. Expression levels of miR-1-3p in RCC tissues and adjacent renal normal tissues (RNT) were then evaluated. Results shown that miR-1-3p expression in RCC tissues was significantly lower compared within the RNT $(P<0.01$; Figure 1B). Downregulation of miR-1-3p was significantly associated with capsulation, lymph node migration and vascular invasion $(P<0.01$; Figure $1 C)$. These findings suggest that miR-1-3p may negatively correlate with migration and invasion of RCC.

\section{miR-I-3p inhibits the invasion and metastatic property of RCC cells}

To define the character of miR-1-3p in RCC invasion and migration, miR-1-3p or Mock Control (MC) miRNA was transfected into A498 or CAKI-1 cells to explore the effects of miR-1-3p upregulation on the invasion and migration of RCC cell lines, respectively. NonTransfected (NT) A498 or CAKI-1 cells were used as blank control cells. RT-PCR results shown that miR-1-3p transfection-elevated expression level of miR-1-3p for nearly 100-fold increase compared with control groups after 48 hrs transfection $(P<0.01$; Figure $2 \mathrm{~A})$.

The role of miR-1-3p in A498 or CAKI-1 RCC cells was then assessed by invasion and migration assay on RCC cells that were transfected with miR-1-3p. Chiefly, we studied the effects of miR-1-3p on the proliferative property of RCC cells by means of the CCK- 8 assay. Results revealed that miR-1-3p expression improvement significantly blocked cell proliferation compared with $\mathrm{MC}$ and NT groups $(P<0.01$; Figure 2B), demonstrating that miR-1-3p expression level might be interconnected with the proliferation potential of RCC cells. Matched with the control groups, the number of A498 or CAKI-1 cells transfected with miR-1-3p that 
A

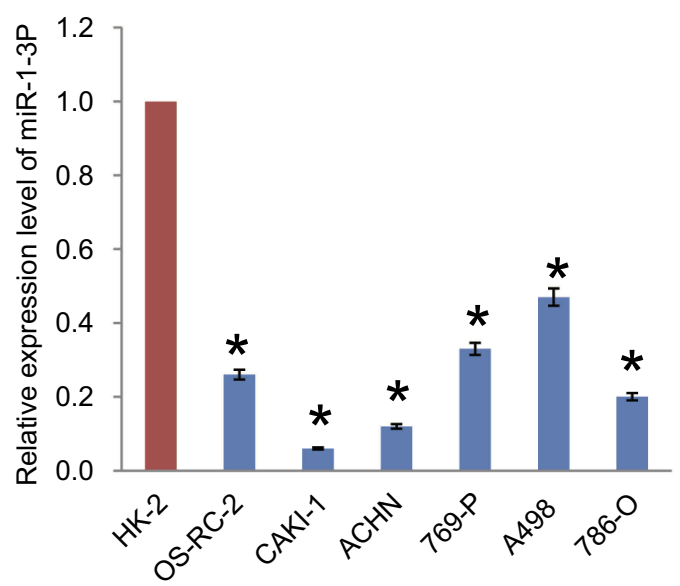

B

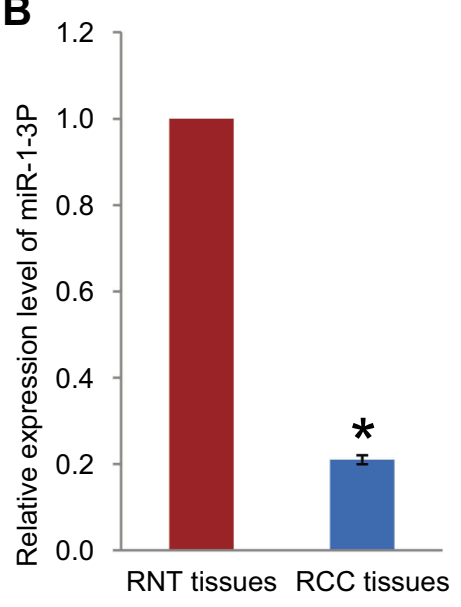

C

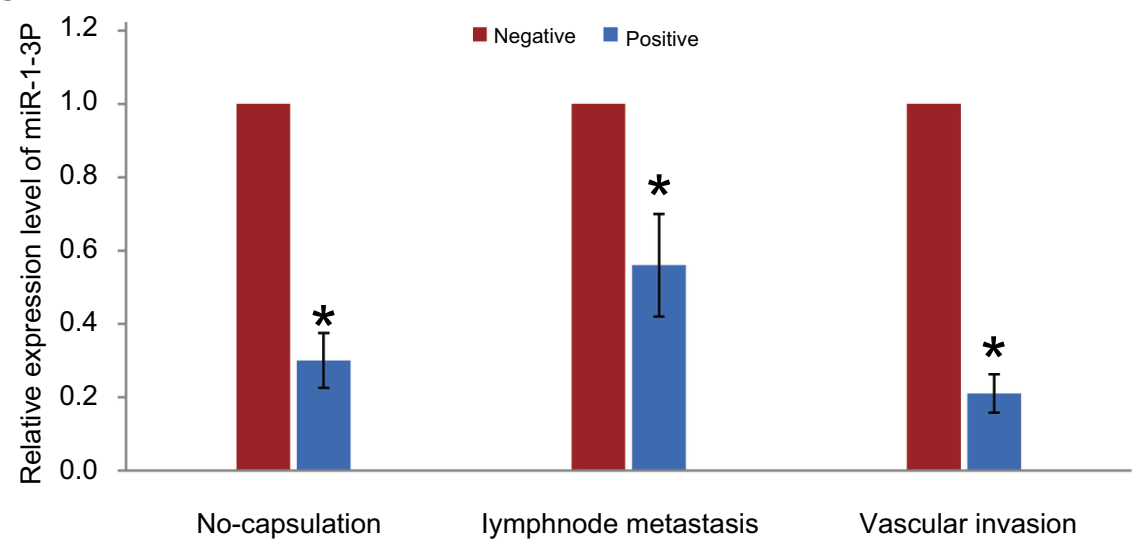

Figure I (A) Expression of miR-I-3p in the RCC cell lines OS-RC-2, CAKI-I, ACHN, 769-P, A498, and 786-O was significantly downregulated compared with the immortal renal cell line HK-2. (B) Expression levels of miR-I-3p in RCC tissues and adjacent renal normal tissues (RNT) were analyzed by RT-PCR assay. (C) miR-I-3p expression levels were compared in RCC tissues with or without capsulation, lymphnode metastasis or vascular invasion. $* P<0.01$ vs HK-2, RNT or negative.

Abbreviations: RCC, renal cell carcinoma; miR, microRNA.

traversed the Matrigel was significantly lesser $(P<0.01$; Figure 2C). Also, the wound-healing assay confirmed the role of miR-1-3p in the migration property of RCC cells. The wound-healing property of A498 or CAKI-1 cells in the miR-1-3p group was apparently suppressed compared with that in control groups $(P<0.01$; Figure 2D). Therefore, we verify that miR-1-3p is a key controller in the proliferation, invasion, and migration potential of RCC cells.

\section{miR-I-3p may inhibit the invasion and migration of RCC cells by regulating the EMT process}

The invasion and migration of cancer cells are often related to the changes of EMT process. To evaluate the character of miR-1-3p in regulating the EMT in RCC, mRNA, and protein expression levels of the epithelial marker E-cadherin and the mesenchymal marker and transcription factor Slug in
A498 or CAKI-1 cells were measured by RT-PCR assay and Western blotting assay. As demonstrated in Figure 3A and $\mathrm{B}, \mathrm{RCC}$ cells in the miR-1-3p group resulted in noteworthy upregulation of the mRNA and protein expression levels of E-cadherin compared with MC or NT groups $(P<0.01)$. Besides, the mRNA and protein expression levels of Slug were significantly declined compared with the control groups $(P<0.01$, Figure 3A, B). Accordingly, miR-1-3p was determined to inhibit invasion and migration potential of RCC cells by regulating the EMT process. Consequently, miR-1-3p might be targeted as EMT-associated invasion and migration suppress target in RCC.

\section{miR-I-3p inhibits EMT by directly targeting Fibronectin I}

miRNAs take effect on cancer cells by controlling the posttranscriptional process of specific target proteins. Even 
A

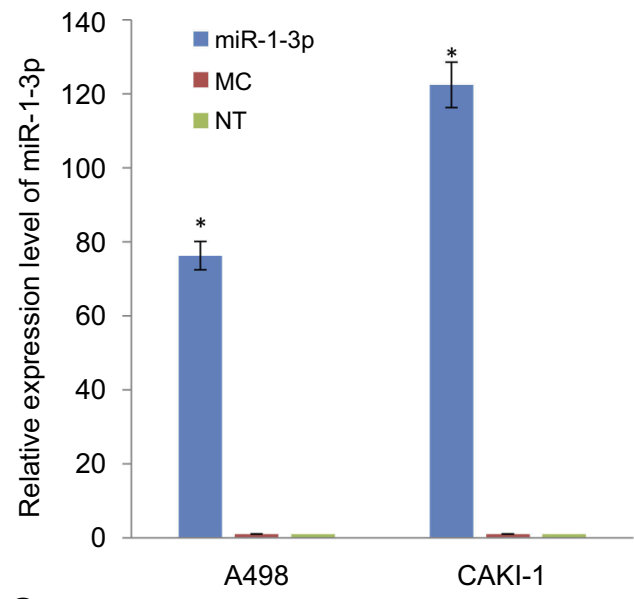

C

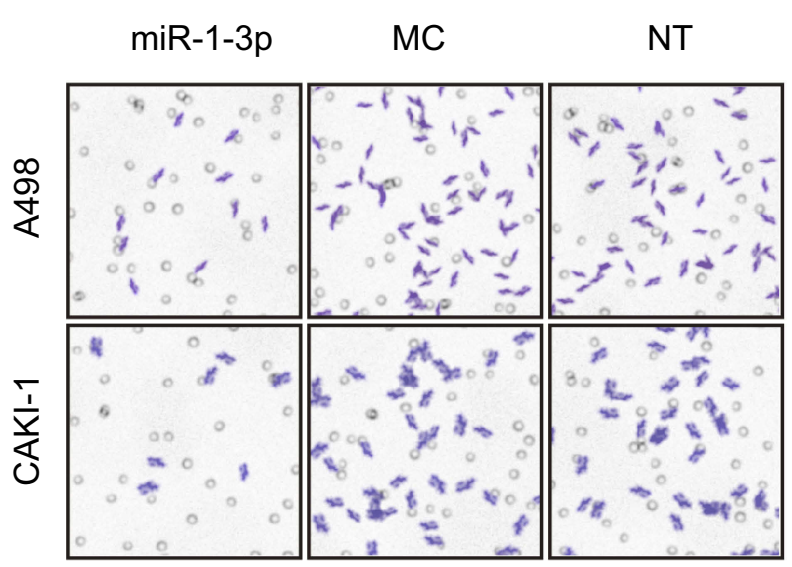

D

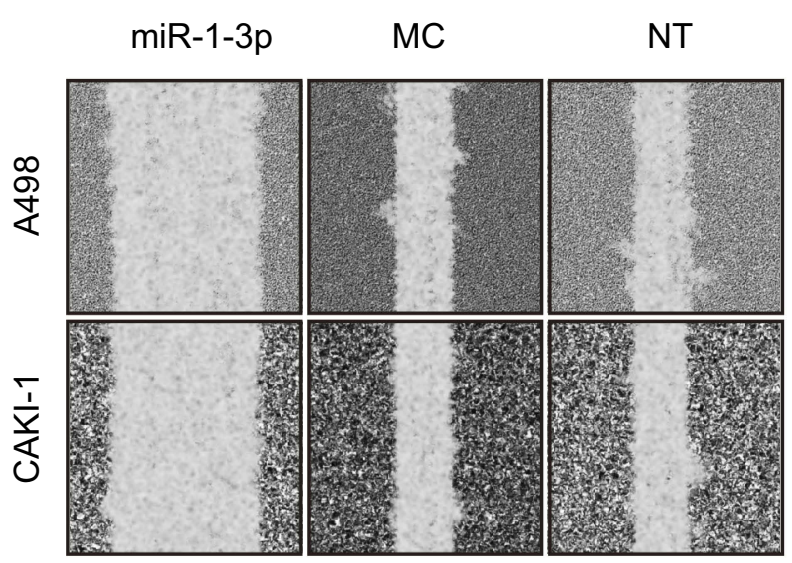

B
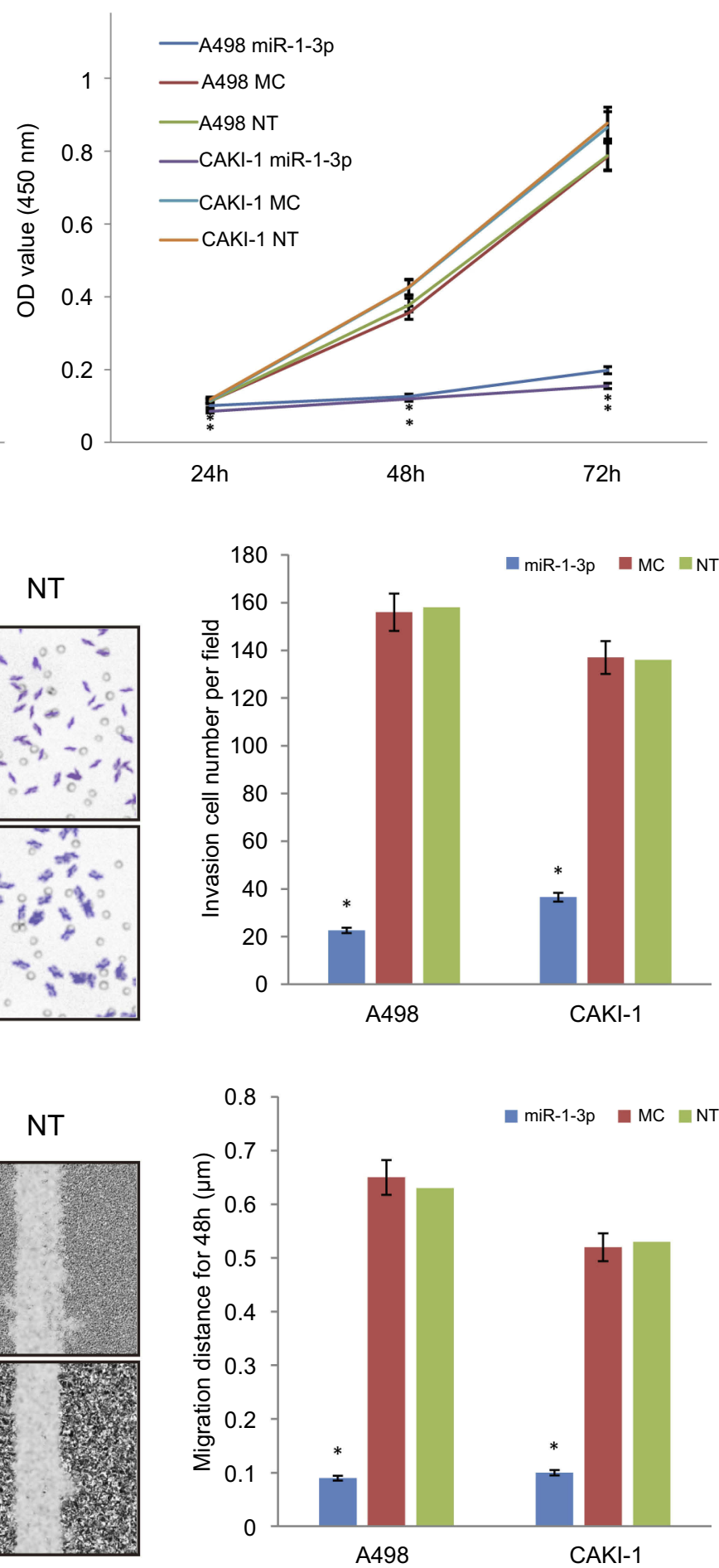

Figure 2 Upregulation of miR-I-3p repressed the proliferation, invasion, and migration of RCC cells. Transfection with miR-I-3p significantly increased the expression of miR-I-3p in (A) A498 and CAKI-I cells compared with cells transfected with MC miRNA or Non-Transfected cells. (B) A CCK-8 assay was used to study the proliferative property of A498 and CAKI-I cells at 24, 48 ,and 72 hrs after transfection with miR-I-3p. (C) Results of a Transwell assay shown that increase of miR-I-3p considerably decreased the number of A498 and CAKI-I cells that invaded over the membrane compared with Non-Transfected cells (200x magnification, first panel of the figure is a representative illustration of the results). (D) Increase of miR-I-3p considerably reduced the wound healing distance of A498 and CAKI-I cells compared with NonTransfected cells ( $100 \times$ magnification, first panel of the figure is a representative illustration of the results). A498 or CAKI-I transfected with Mock Control (MC) miRNA or Non-Transfected (NT) cells were used as controls, respectively. ( $=3, * P<0.0$ I vs Non-Transfected cells).

Abbreviations: RCC, Renal cell cancer; CCK-8, Cell counting kit-8. 

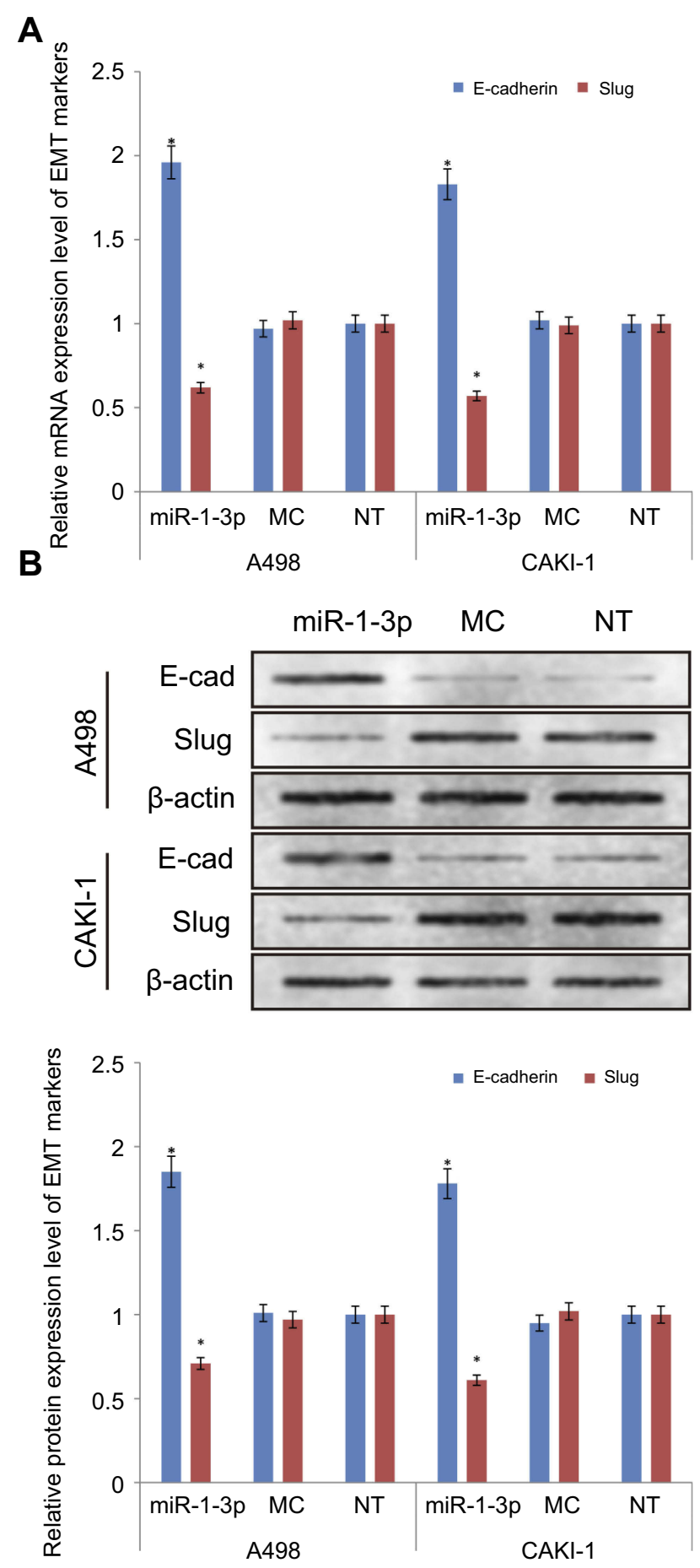

Figure 3 Increase of miR-I-3p level inhibited the origination of the EMT process in RCC cells. RT-PCR assay or Western blot assay were used to detect the (A) mRNA or (B) protein expression levels of the epithelial marker E-cadherin and the mesenchymal marker and transcription factor Slug in A498 or CAKI-I cells. Results shown that mRNA or protein expression of E-cadherin was improved in the miR-I-3p group compared with control groups, although the mRNA or protein expression levels of Slug was decreased in A498 or CAKI-I cells treated with miR-I-3p compared with control groups. (The first panel of $(B)$ is a representative illustration of the results; $n=3$, $* P<0.0$ I vs Non-Transfected cells).

Abbreviations: EMT, Epithelial-mesenchymal transition, RCC, Renal cell cancer.

though the role of miR-1-3p in the development of numerous cancers has been previously revealed, the mechanism by which miR-1-3p regulate invasion and migration has not been demonstrated an undisputed conclusion. Fibronectin 1, a tumor promoter and important EMT marker, is known to regulate the invasion and migration in cancer cells. After bioinformatics prediction, miR-1-3p was shown to have a biding site in the $3^{\prime}$-UTR of Fibronectin 1 (Figure 4A). To explore whether Fibronectin 1 was a functional target of miR1-3p in RCC cells, miR-1-3p was co-transfected with WTFibronectin 1-3'UTR or MUT-Fibronectin 1-3'UTR plasmid into RCC cells. As illustrated in Figure 4A, RCC cells cotransfected with miR-1-3p and WT-Fibronectin 1-3'UTR plasmid presented a statistically obviously decline in reporter activity compared with RCC cells co-transfected with Mock miRNA and WT-Fibronectin 1-3'UTR plasmid $(P<0.01)$. Additionally, RCC cells co-transfected with miR-1-3p and MUT-Fibronectin 1-3'UTR plasmid or Mock miRNA with MUT-Fibronectin 1-3'UTR revealed no considerable alteration in reporter activity $(P>0.01)$. Thus, the luciferase activity of the wild type Fibronectin 1-3'-UTR but not the mutated Fibronectin 1-3'-UTR reporter was diminished by miR-1-3p. To additional support the regulatory properties of miR-1-3p on Fibronectin 1, RT-PCR assay and Western blot assay were employed to measure expression levels of Fibronectin 1 in different groups of RCC cells. Results revealed that upregulation of miR-1-3p in A498 or CAKI-1 cells resulted in a considerable decrease of $\mathrm{mRNA}$ and protein expression levels of Fibronectin $1 \quad(P<0.01$; Figure 4B, C). Contrariwise, the mRNA and protein expression of Fibronectin 1 in A498 or CAKI-1 cells in the MC group revealed no significant difference matched with NT cells (Figure 4B, C). These results shown that miR-1-3p probably will directly control Fibronectin 1 expression level by binding to the 3'-UTR of Fibronectin 1 in A498 or CAKI-1 RCC cells.

\section{Fibronectin I may rescue the inhibitory effect of miR-I-3p on invasion and migration potential of RCC cells}

Fibronectin 1 has been proved to join in invasion and migration in cancer cells. With the purpose of evaluate whether miR-1-3p contributes in the invasion and migration of RCC by regulating the expression level of Fibronectin 1, the Fibronectin 1 eukaryotic expression plasmid was produced and co-transfected into A498 or CAKI-1 cells accompanied with miR-1-3p. The Fibronectin 1 expression vector transfected alone; miR-1-3p transfected alone; or non-transfected A498 or CAKI-1 cells were used as control groups. In A498 or CAKI-1 cells, expression levels of Fibronectin 1 were significantly increased in the 


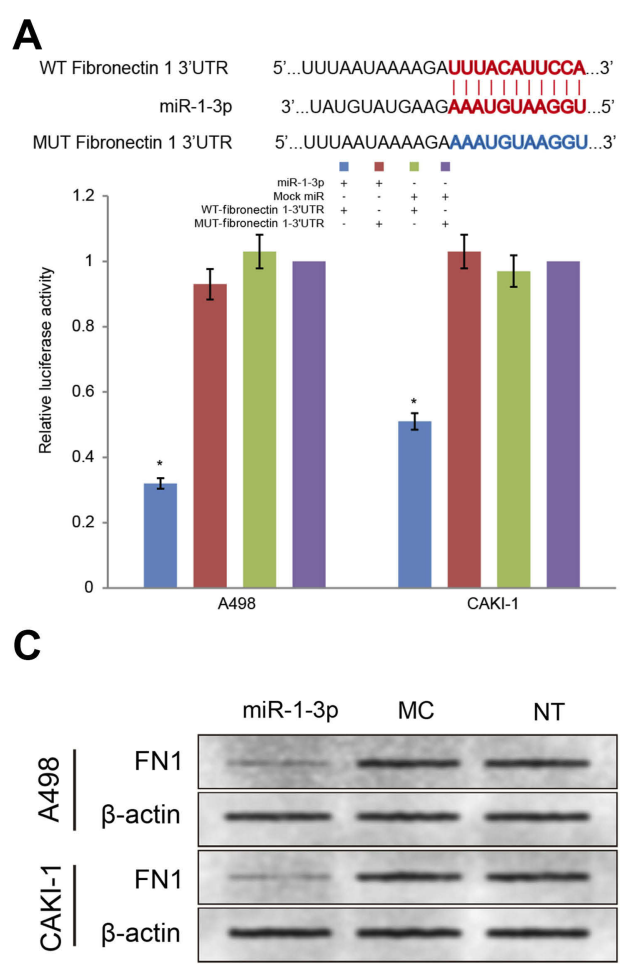

B
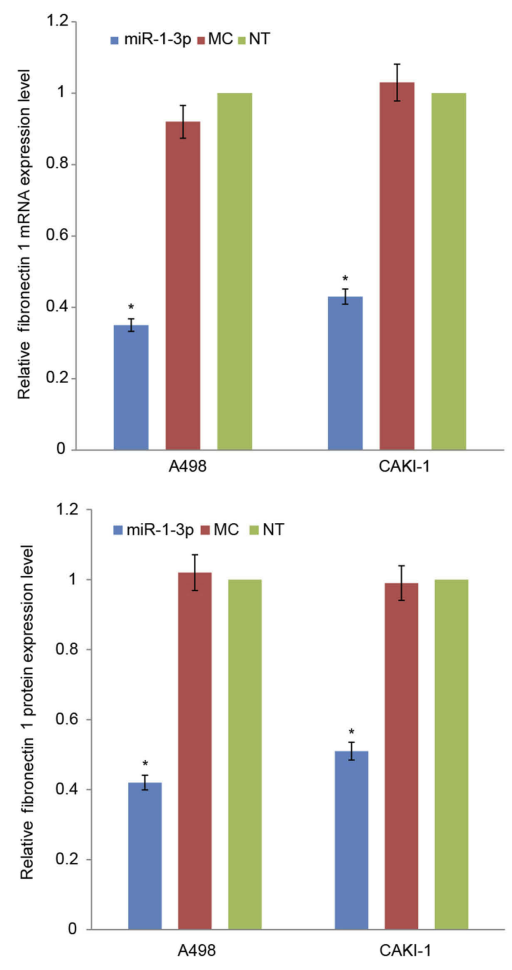

Figure 4 Fibronectin I was directly targeted by miR-I-3p via its 3'-UTR region. (A) A luciferase activity assay was used to detect the reporter activity in A498 or CAKI-I cells co-transfected with either miR-I-3p mimics or Mock Control miRNA, and either WT-Fibronectin I-3'UTR or MUT-Fibronectin I-3'UTR. The mutant miR-I-3p binding site was generated in the complementary site for the seed region of miR-I-3p. $(n=3, * P<0.0$ I vs the Mock Control miRNA and MUT-Fibronectin I-3'UTR co-transfected cells). The relative (B) mRNA or (C) protein expression levels of Fibronectin I in A498 or CAKI-I cells with or without miR-I-3p were determined. $\boldsymbol{\beta}$-actin was used as an internal control. (The first panel of $(\mathbf{C})$ is a representative illustration of the results; $n=3, * P<0.01$ vs Non-Transfected cells).

Abbreviations: UTR, untranslated regions; WT, wild type; MUT, mutant.

Fibronectin 1 expression vector-transfected groups matched with the Non-Transfected groups $(P<0.01$; Figure 5A, B). Besides, expression levels of Fibronectin 1 protein were considerably increased in the Fibronectin 1 plasmid vector and miR-1-3p co-transfected groups compared with the miR-1-3p transfected alone group $(P<0.01$; Figure 5A, B). A Matrigelcoated Transwell assay and a wound healing assay were employed once more to assess the invasive and metastatic potential of different groups of A498 or CAKI-1 cells. Significant changes were identified in the Fibronectin 1 expression upregulated groups $(P<0.01)$, and the Fibronectin 1 eukaryotic expression vector and miR-1-3p co-transfected groups $(P<0.01)$ in A498 and CAKI-1 RCC cells. A significant rescue effect in invasion and migration property was recognized in the Fibronectin 1 plasmid and miR-1-3p co-transfected group in A498 or CAKI-1 cells, compared with the miR-1-3p transfected alone group $(P<0.01$; Figure 5C, D). Briefly, miR-1-3p is possibly a fundamental controller in invasion and migration properties of RCC cells, which may arise via regulating Fibronectin 1 protein expression level.

\section{Reload of Fibronectin I rescued of the EMT inhibitory effect of miR-I-3p}

Fibronectin 1 was confirmed as a direct target gene of miR$1-3 p$ through luciferase assay and Western blot analysis in RCC cells. miR-1-3p controls the expression level of Fibronectin 1 protein by binding to its 3'UTR. However, whether Fibronectin 1 contributes to the miR-1-3p-controlled EMT process in RCC remains unclear. The mRNA and protein expression levels of E-cadherin in A498 and CAKI-1 cells were significantly reduced, and Slug levels were noticeably increased in Fibronectin 1 eukaryotic expression vector transfection alone group compared with NT cells $(P<0.01$; Figure $6 \mathrm{~A}, \mathrm{~B})$. Similar rescue effect on EMT markers was validated in RCC cells co-transfected with Fibronectin 1 eukaryotic expression plasmid and miR-1-3p compared with cells transfected with miR-1-3p alone $(P<0.01$; Figure 6A, B). It was shown that reload of Fibronectin 1 in A498 or CAKI-1 cells obviously rescued the suppression effect on the EMT process by miR-1-3p. The results of the current in vitro studies reveal 

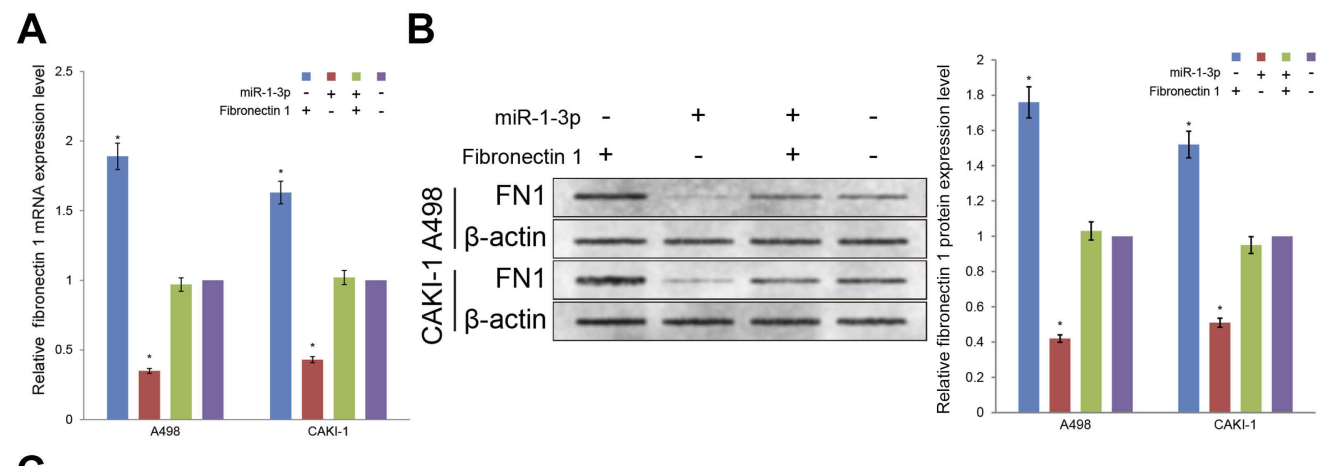

C
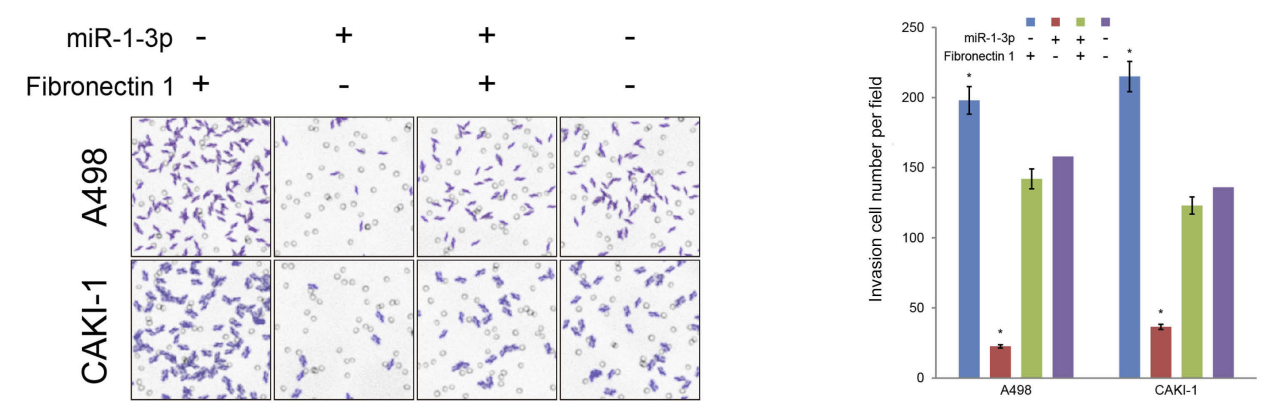

D
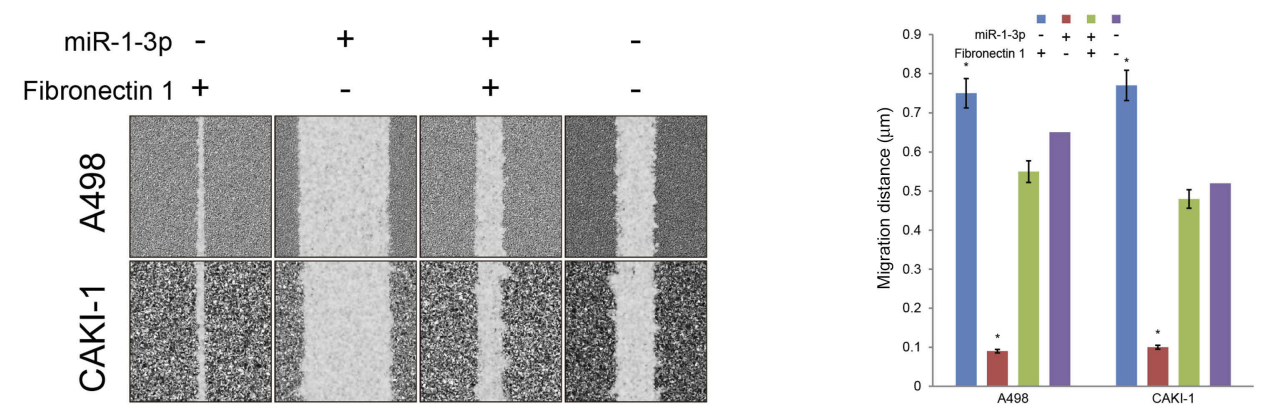

Figure 5 Upregulation of Fibronectin I partially rescued the invasion and migration potential of RCC cells. Transfection of Fibronectin I plasmid can rescue the miR-I-3pinduced reduction in (A) mRNA and (B) protein expression levels of Fibronectin I in A498 or CAKI-I cells. The invasion property (C) and the migration property (D) of A498 or CAKI-I cells were surveyed by a Transwell assay and a wound healing assay, respectively. Transfection of Fibronectin I plasmid also rescued the miR-I-3p-induced reduction in invasion and migration property. (The first panel of $(\mathbf{B}, \mathbf{C}$, and $\mathbf{D})$ are representative illustration of the results; $n=3$, $* P<0.01$ vs untransfected cells).

that miR-1-3p suppresses the EMT process by target control of Fibronectin 1 protein expression. Furthermore, we studied the relationship between the expression level of miR-1-3p and Fibronectin $1 \mathrm{mRNA}$ in the preceding clinical specimens of renal cell carcinoma. The results showed that the expression level of miR-1-3p was negatively correlated with that of Fibronectin-1 mRNA ( $\mathrm{R}=-0.184$, Figure $6 \mathrm{C}$ ). These results further confirmed the negative regulatory effect of miR-1-3p on Fibronectin 1 in primary renal cell carcinoma cells.

\section{miR-I-3p inhibits EMT process in vivo in RCC xenograft model}

In order to further investigate the tumor inhibitory effect of miR-1-3p in RCC, we established a xenograft model to explore the effect of miR-1-3p in vivo (Figure 7). A498 or
CAKI-1 cells with the enhanced expression level of miR$1-3 p$ or Mock miR were injected into nude mice subcutaneously. Mice were killed at 28 days after injection of tumor cells and measurements were made weekly. The growth rates of the A498 or CAKI-1 tumors were traced by tumor volume. Tumor growth rates were considerably suppressed by upregulation of miR-1-3p (Figure 7A, B). These results specified that miR-1-3p has a suppressive effect in RCC in vivo. To additionally confirm whether this in vivo suppressive effect in RCC is concerned with a variation of Fibronectin 1 protein expression and a change of the EMT process, we applied immunohistochemistry assay and Western blotting assay to identify the expression level of Fibronectin 1, E-cadherin or Slug proteins in A498 and CAKI-1 tumor tissues. Experiment result confirmed that expression levels of mesenchymal 
A

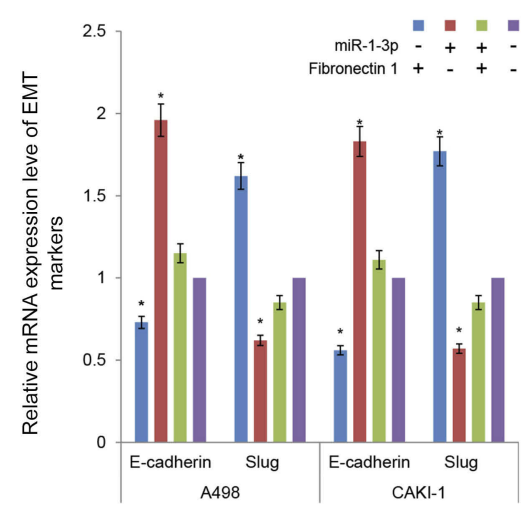

C

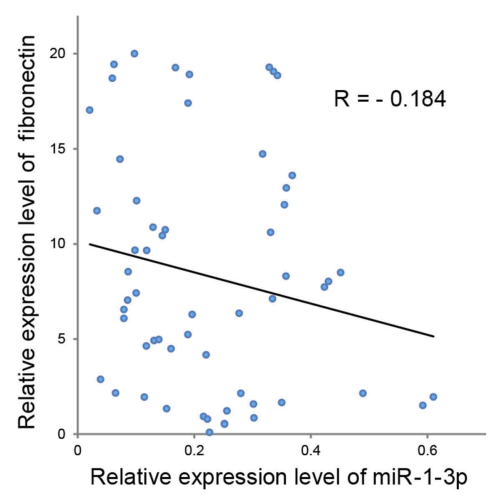

B
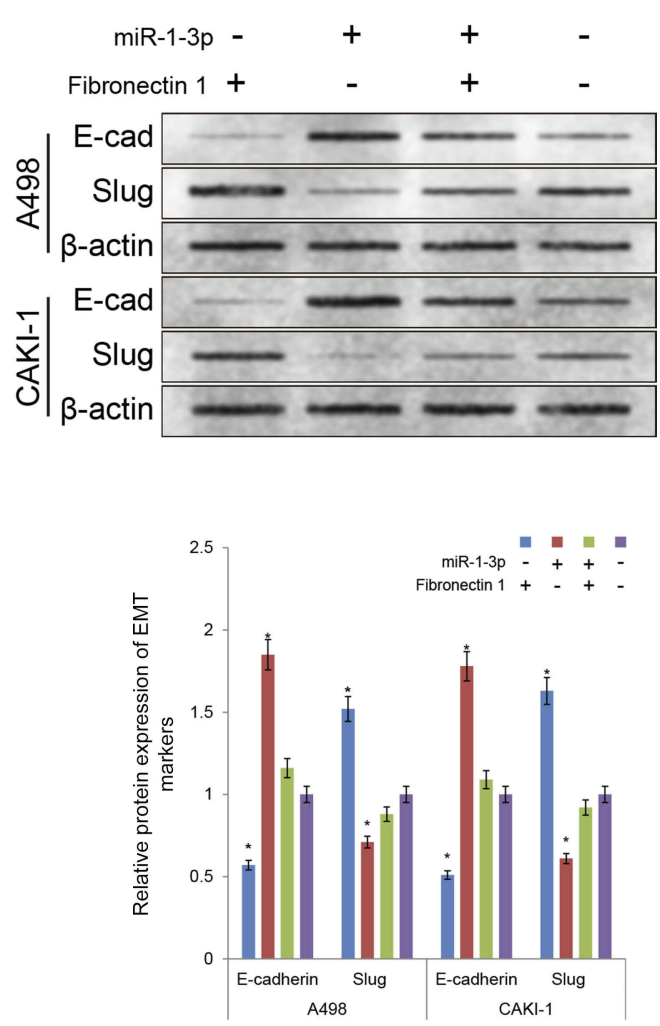

Figure 6 Upregulation of Fibronectin I partially rescued the EMT property blocked by miR-I-3p. Results of the RT-PCR assay and Western blot assay were used to determine the (A) mRNA and (B) protein expression levels of E-cadherin and Slug in A498 or CAKI-I cells that were untransfected, transfected with either Fibronectin I eukaryotic expression vector or miR-I-3p mimic alone, or co-transfected. (The first panel of $(\mathbf{B})$ is a representative illustration of the results; $n=3$, $* P<0.0 I$ vs untransfected cells). (C) The relationship between the relative expression level of miR-I-3p and Fibronectin I mRNA in RCC tissues was determined by RT-PCR assay. Abbreviation: EMT, Epithelial-mesenchymal transition.

marker Fibronectin 1 and the mesenchymal marker and transcription factor Slug were considerably reduced, and the epithelial marker E-cadherin expression level was increased in miR-1-3p-upregulated A498 or CAKI-1 tumors (Figure $7 \mathrm{C}, \mathrm{D}, P<0.01$ ).

Briefly, the results of the in vivo study maintained the results of in vitro studies and presented that miR-1-3p/ Fibronectin 1 axis plays a significant role in inhibiting the invasion and migration potential via regulating the EMT of RCC cells.

\section{Discussion}

miRNAs have been confirmed to be associated with the proliferation, apoptosis, invasion, and migration of malignancy cancer, by acting as tumor suppressors or oncogenes. ${ }^{52,53}$ Previous studies have clarified the irregular expression levels of several miRNAs in RCC together with miR-1-3p. miR-1-3p have been validated to be reduced in numerous different types of cancer, including lung cancer, ${ }^{54}$ colorectal carcinoma ${ }^{55}$, and urinary neoplasms. But the role and function of miR-1-3p in malignancy disease have not been definitely illuminated. Wang et al, revealed that miR-1-3p inhibit lung cancer by c-Met signaling and EMT process. ${ }^{55}$ Gao et al, demonstrated that miR-1-3p inhibits cell proliferation and invasion by regulating the BDNF-TrkB signaling pathway in bladder cancer. ${ }^{56}$ Additionally, Wang et al, reported that miR1-3p inhibits the proliferation and invasion of bladder cancer cells by suppressing CCL2 expression. ${ }^{57}$ However, the function of miR-1-3p in RCC has not been inspected thoroughly. In the current study, it was revealed that expression level of miR-1-3p in the RCC cell lines was significantly depressed compared with the normal renal cell line, suggesting that the reduction of miR-1-3p expression level may encourage the initiation and development of RCC. Along with the data that was explored in RCC cells, the relationship of expression levels of miR$1-3 p$ in clinical RCC tissues and clinic-pathological data 


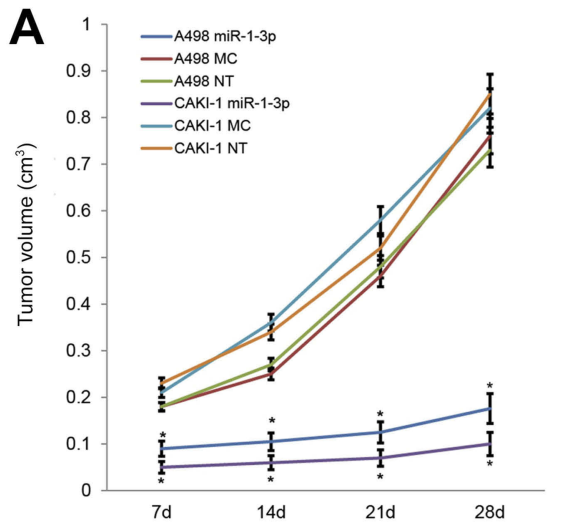

B
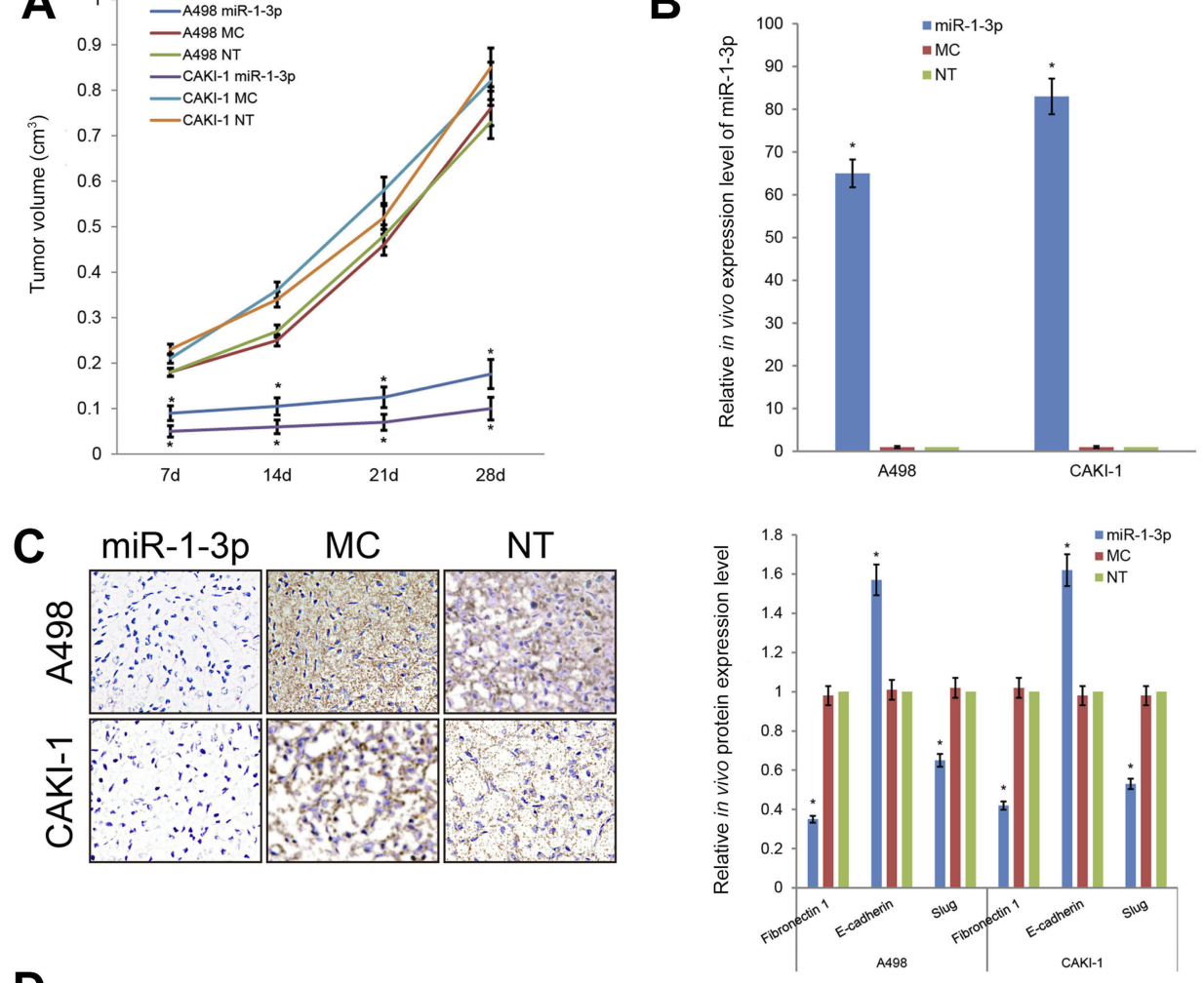

D

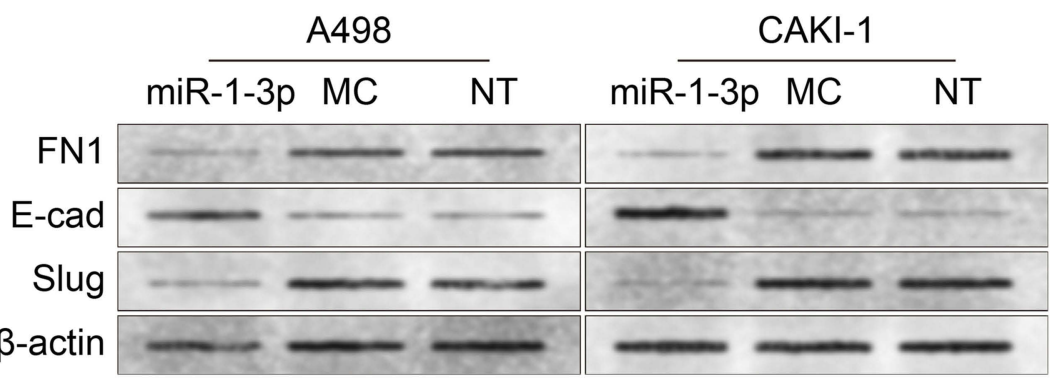

Figure 7 (A) Upregulation of miR-I-3p repressed the growth of A498 and CAKI-I RCC cell xenograft models. (B) Expression level of miR-I-3p in xenograft tumors of nude mice evaluated by RT-PCR assay. (C) Expression level of Fibronectin I in xenograft tumors observed by immunohistochemistry staining. (D) Protein expression levels of Fibronectin I, E-cadherin or Slug in xenograft tumors of nude mice evaluated by Western blotting assay ( $n=6, * P<0.0$ I vs Non-Transfected groups). (The first panel of (C and $\mathbf{D})$ are representative illustration of the results).

were further investigated. miR-1-3p was shown to be significantly suppressed in RCC tissues compared with RNT tissues. Moreover, a meaningful relationship was also discovered between the miR-1-3p levels with capsulation, lymph node migration, and vascular invasion, demonstrating that the expression of miR-1-3p also had a remarkable function in RCC invasion and migration.

To further study the character of miR-1-3p in RCC, miR-1-3p was transfected into RCC cells. Expression levels of miR-1-3p raised obviously in A498 or CAKI1 cells transfected with miR-1-3p transfected. Upregulated expression of miR-1-3p substantially decreased the proliferation, invasion, and migration of RCC cells. These consequences additionally verify the clinic-pathological data that miR-1-3p may have a function of inhibiting proliferation, invasion, and migration of RCC cells.

The EMT property serves an essential occupation in RCC invasion and metastasis. Further evidence has revealed that miRNAs are involved in controlling the EMT potential in various types of cancer cells. Bhat et al, ${ }^{58}$ indicated that miR-30b-5p acts as a novel tumor suppressor to regulate RCC cell proliferation, metastasis, and EMT through downregulation of GNA13 expression. Yamasaki et al, ${ }^{59}$ pointed out that miR-138 functions as a tumor suppressor in RCC by regulating the EMT process. Therefore, the definite function of miR-1-3p in the EMT process in RCC cells needs to be explored 
thoroughly. In this study, it was proved that accompanied with an elevation of miR-1-3p, the mRNA and protein expression levels of the epithelial marker E-cadherin were extensively upregulated, while the expression levels of the mesenchymal marker and transcription factor Slug were obviously downregulated. Accordingly, it can be concluding that miR-1-3p theoretically regulates the invasion and migration of RCC cells by controlling its EMT process. miRNAs constantly effect through binding to the 3'UTRs areas of special-targeted genes, and some primary studies have investigated targeted genes of miR-1-3p in various cancer types. But targeted genes of miR-1-3p in RCC cells remain lack of reporting up to now. In the present study, it was demonstrated that increase of miR1-3p may lead to obvious reduce on the expression level of Fibronectin 1 in RCC cells. Fibronectin 1 is a matrix glycoprotein that increased in several carcinoma cell types, including RCC. ${ }^{60}$ In recent years, Fibronectin 1 has been gradually certified as an oncogene, which regulates metastasis in various cancers include RCC. It is also one of the main functional markers and regulatory factors of EMT. ${ }^{61}$ Through cell transfection and luciferase reporter assays, it was also confirmed that Fibronectin 1 was a direct target gene of miR-1-3p. It was further confirmed that the rescue expression of Fibronectin 1 protein in RCC cells co-transfected with miR-1-3p may reverse the effects on invasion and migration caused by miR-1-3p increasing obviously. Moreover, reload of Fibronectin 1 rescued the miR-1-3p-induced suppression of the EMT process. In particular, the increased expression of Fibronectin 1 attenuates the inhibitory effect of miR-1-3p on mesenchymal marker and transcription factor Slug. Previous studies closely related to this study found that RCC cells exhibited increased levels of expression of Fibronectin, and then induced upregulation of the transcription factor Slug, which mediates EMT process. ${ }^{62}$ This conclusion strongly supports our research results. These effects correspondingly confirmed that miR-1-3p suppressed the invasion and migration of RCC cells through targeting of the Fibronectin 1-mediated EMT. Interestingly, the interaction mechanism of EMT markers is very complex. For example, Slug is reported to down-regulate the adhesion protein E-cadherin as a transcription factor. ${ }^{63-65}$ Therefore, the interaction between these EMT markers can help to explain some of the results we obtained. Even more intriguingly, Slug itself has been previously shown to be a direct target of miR-1 with a binding site in its 3'-UTR in chordoma, lung cancer, oral squamous cell carcinoma, and glioma cells. ${ }^{66-70}$ This direct targeting inhibitory effect is likely to exist in RCC as well. At the same time, it also helps us to explain that the increased expression of Fibronectin 1 cannot completely rescue the inhibition of miR-1-3p on invasion and metastasis.

Then, we further explored the relationship between the expression level of miR-1-3p and Fibronectin 1 mRNA in clinical specimens, and found that there was a significant negative correlation between their expression levels. These results suggest that they may also be closely related clinically. Previous reports also suggest a negative correlation between the survivals of renal cancer patients. For example, Xiao et al, reported that miR-1 was significantly downregulated in RCC samples compared with corresponding non-cancerous tissues, which was significantly associated with poor patients' prognosis. ${ }^{22}$ On the contrary, several studies have suggested that, higher Fibronectin 1 expression level may demonstrate a higher disease-related mortality rate and poorer outcome in RCC patients. ${ }^{71-73}$

To further clarify the role of miR-1-3p in RCC, in vivo studies were conducted. In vivo studies shown that miR$1-3 p$ transfection effectively reduced the growth rates of subcutaneous tumors. Moreover, expression levels of the Fibronectin 1 protein and EMT markers were confirmed to have the same trend as the in vitro EMT studies. Accordingly, the present study has verified a novel regulatory target of miR-1-3p/Fibronectin 1 axis in RCC consistent with strong in vitro and in vivo evidence. It must be noted that, due to the complexity of the regulation mechanisms, linear relationship between miR-1-3p/ Fibronectin 1 and EMT may be presented as one of several pathways that could lead from the downregulation of miR$1-3 p$ to increased proliferation, invasion , and metastasis of RCC. In addition, significant advantages have been made in cancer therapy technique during the last decade; accompanied by our understanding of carcinogenesis regulated by interconnecting networks of cellular signaling pathways. Insights into these carcinogenesis pathways have exposed many novel cancer targets for which therapeutic agents for clinical application may be developed. ${ }^{74}$ As far as we know, related tumor inhibitors have not been reported yet, but we can expect to develop novel RCC treatment targeting miR-1-3p/Fibronectin 1 axis as a specific inhibitor. ${ }^{75}$

In conclusion, the evidence from the present study revealed that miR-1-3p was decreased significantly in $\mathrm{RCC}$ cell lines and clinical tissues, particularly in RCC 
tissues with capsulation absence, lymph node migration, and vascular invasion. Moreover, it was further confirmed that the role of miR-1-3p in RCC was depended on Fibronectin 1-mediated EMT process directly. Accordingly, the miR-1-3p/Fibronectin 1 axis may be a potential therapeutic target for advancement of $\mathrm{RCC}$ drug development.

\section{Abbreviation list}

RCC, Renel cell cancer; EMT, Epithelial-mesenchymal transition; miR, MicroRNA; 3'-UTR, 3'-untranslated regions; miR-1-3p, microRNA-1-3p; CCK-8, Cell counting kit-8 assay; OD, optical density; IACUC, Institutional Animal Care and Use Committee; SD, standard deviation; RNT, adjacent renal normal tissues; NT, Non-Transfected cells; MC, Mock Control cells.

\section{Acknowledgments}

Special thanks to the reviewers and editors for their help in improving the quality of the manuscript. This study was supported by the Science and Technology Project of Guangdong Province of China (2016A010103012), Guangdong Medical Research Foundation (C2017056). The funders supported the purchase of necessary laboratory reagents and the rental of laboratory instruments. The funders had no role in study design, data collection, and analysis, decision to publish, or preparation of the manuscript.

\section{Disclosure}

The authors report no conflicts of interest in this work.

\section{References}

1. Bukowski RM. Metastatic clear cell carcinoma of the kidney: therapeutic role of bevacizumab. Cancer Manag Res. 2010;2:83-96.

2. Speed JM, Trinh QD, Choueiri TK, Sun M. Recurrence in localized renal cell carcinoma: a systematic review of contemporary data. Curr Urol Rep. 2017;18:15. doi:10.1007/s11934-017-0661-3

3. Abel EJ, Margulis V, Bauman TM, et al. Risk factors for recurrence after surgery in non-metastatic RCC with thrombus: a contemporary multicentre analysis. BJU Int. 2016;117:E87-E94. doi:10.1111/bju.13268

4. He H, Magi-Galluzzi C. Epithelial-to-mesenchymal transition in renal neoplasms. Adv Anat Pathol. 2014;21:174-180. doi:10.1097/ PAP.0000000000000018

5. Sciacovelli M, Frezza C. Metabolic reprogramming and epithelial-tomesenchymal transition in cancer. Febs J. 2017;284:3132-3144. doi:10.1111/febs.14090

6. Lo UG, Lee CF, Lee MS, Hsieh JT. The role and mechanism of epithelial-to-mesenchymal transition in prostate cancer progression. Int J Mol Sci. 2017;18. doi:10.3390/ijms18102079.
7. Wang J, Ou J, Guo Y, et al. TBLR1 is a novel prognostic marker and promotes epithelial-mesenchymal transition in cervical cancer. $\mathrm{Br}$ $J$ Cancer. 2014;111:112-124. doi:10.1038/bjc.2014.278

8. Guo Y, Wu Z, Shen S, et al. Nanomedicines reveal how PBOV1 promotes hepatocellular carcinoma for effective gene therapy. Nat Commun. 2018;9:3430. doi:10.1038/s41467-018-05764-7

9. Phillips S, Kuperwasser C. SLUG: critical regulator of epithelial cell identity in breast development and cancer. Cell Adh Migr. 2014;8:578-587. doi:10.4161/19336918.2014.972740

10. Wong S, Fang CM, Chuah LH, Leong CO, Ngai SC. E-cadherin: its dysregulation in carcinogenesis and clinical implications. Crit Rev Oncol Hematol. 2018;121:11-22. doi:10.1016/j.critrevonc.2017.11.010

11. Harada K, Miyake H, Kusuda Y, Fujisawa M. Expression of epithelial-mesenchymal transition markers in renal cell carcinoma: impact on prognostic outcomes in patients undergoing radical nephrectomy. BJU Int. 2012;110:E1131-E1137. doi:10.1111/j.1464410X.2012.11297.x

12. Chipman LB, Pasquinelli AE. miRNA Targeting: growing beyond the Seed. Trends Genet. 2019;35:215-222. doi:10.1016/j.tig.2018.12.005

13. Xie M, Lv Y, Liu Z, et al. Identification and validation of a four-miRNA (miRNA-21-5p, miRNA-9-5p, miR-149-5p, and miRNA-30b-5p) prognosis signature in clear cell renal cell carcinoma. Cancer Manag Res. 2018;10:5759-5766. doi:10.2147/CMAR.S187109

14. Zhang J, Wang L, Mao S, et al. miR-1-3p contributes to cell proliferation and invasion by targeting glutaminase in bladder cancer cells. Cell Physiol Biochem. 2018;51:513-527. doi:10.1159/000495273

15. Li SM, Wu HL, Yu X, et al. The putative tumour suppressor miR-1-3p modulates prostate cancer cell aggressiveness by repressing E2F5 and PFTK1. J Exp Clin Cancer Res. 2018;37:219. doi:10.1186/s13046-018-0895-z

16. Ahrend H, Kaul A, Ziegler S, et al. MicroRNA-1 and MicroRNA-21 individually regulate cellular growth of non-malignant and malignant renal cells. In Vivo. 2017;31:625-630. doi:10.21873/invivo.11103

17. Kawakami K, Enokida H, Chiyomaru T, et al. The functional significance of miR-1 and miR-133a in renal cell carcinoma. Eur $J$ Cancer. 2012;48:827-836. doi:10.1016/j.ejca.2011.06.030

18. Ren K, Li Y, Lu H, et al. Long noncoding RNA HOTAIR controls cell cycle by functioning as a competing endogenous rna in esophageal squamous cell carcinoma. Transl Oncol. 2016;9:489-497. doi:10.1016/j.tranon.2016.09.005

19. Di W, Li Q, Shen W, Guo H, Zhao S. The long non-coding RNA HOTAIR promotes thyroid cancer cell growth, invasion and migration through the miR-1-CCND2 axis. Am J Cancer Res. 2017;7:1298-1309.

20. Li L, Sarver AL, Alamgir S, Subramanian S. Downregulation of microRNAs miR-1, -206 and -29 stabilizes PAX3 and CCND2 expression in rhabdomyosarcoma. Lab Invest. 2012;92:571-583. doi:10.1038/labinvest.2012.10

21. Jiang S, Zhao C, Yang X, et al. miR-1 suppresses the growth of esophageal squamous cell carcinoma in vivo and in vitro through the downregulation of MET, cyclin D1 and CDK4 expression. Int J Mol Med. 2016;38:113-122. doi:10.3892/ijmm.2016.2619

22. Xiao H, Zeng J, Li H, et al. MiR-1 downregulation correlates with poor survival in clear cell renal cell carcinoma where it interferes with cell cycle regulation and metastasis. Oncotarget. 2015;6:13201-13215. doi:10.18632/oncotarget.3915

23. Leone V, D'Angelo D, Rubio I, et al. MiR-1 is a tumor suppressor in thyroid carcinogenesis targeting CCND2, CXCR4, and SDF-1alpha. J Clin Endocrinol Metab. 2011;96:E1388-E1398. doi:10.1210/ jc. 2011-0345

24. Gong B, Hu H, Chen J, et al. Caprin-1 is a novel microRNA-223 target for regulating the proliferation and invasion of human breast cancer cells. Biomed Pharmacother. 2013;67:629-636. doi:10.1016/j. biopha.2013.06.006

25. Wang S, Fischer PM. Cyclin-dependent kinase 9: a key transcriptional regulator and potential drug target in oncology, virology and cardiology. Trends Pharmacol Sci. 2008;29:302-313. doi:10.1016/j.tips.2008.03.003 
26. Malumbres M. Cyclin-dependent kinases. Genome Biol. 2014; 15:122. doi:10.1186/gb4184

27. Morales F, Giordano A. Overview of CDK9 as a target in cancer research. Cell Cycle. 2016;15:519-527. doi:10.1080/15384101.2016.1138186

28. Guo Y, Chen W, Wang W, et al. Simultaneous diagnosis and gene therapy of immuno-rejection in rat allogeneic heart transplantation model using a T-cell-targeted theranostic nanosystem. ACS Nano. 2012;6:10646-10657. doi:10.1021/nn3037573

29. Wang J, Jia H, Zhang B, et al. HucMSC exosome-transported 14-3-3zeta prevents the injury of cisplatin to HK-2 cells by inducing autophagy in vitro. Cytotherapy. 2018;20:29-44. doi:10.1016/j. jcyt.2017.08.002

30. Li C, Wu J, Li Y, Xing G. Cytoprotective effect of heat shock protein 27 against lipopolysaccharide-induced apoptosis of renal epithelial HK-2 cells. Cell Physiol Biochem. 2017;41:2211-2220. doi:10.1159/000475636

31. Qiang S, Du ZF, Huang M. Adenovirus-mediated NDRG2 inhibits the proliferation of human renal cell carcinoma cell line OS-RC-2 in vitro. Asian Pac J Trop Med. 2014;7:873-878. doi:10.1016/S19957645(14)60152-8

32. Liao H, Wu Z, Huang X, Qiu Z, Wu H. NMyc downstreamregulated gene 2 suppresses proliferation and induces oncosis of OSRC2 human renal cancer cells. Mol Med Rep. 2015;11:1240-1245. doi:10.3892/mmr.2014.2882

33. Yang H, Song E, Shen G, et al. Expression of microRNA-30c via lentivirus vector inhibits the proliferation and enhances the sensitivity of highly aggressive ccRCC Caki-1 cells to anticancer agents. Onco Targets Ther. 2017;10:579-590. doi:10.2147/OTT.S115791

34. Liu Y, Fu QZ, Pu L, et al. Effect of RNA interference of the expression of HMGA2 on the proliferation and invasion ability of ACHN renal cell carcinoma cells. Mol Med Rep. 2017;16:5107-5112. doi:10.3892/mmr.2017.7258

35. Huang B, Huang YJ, Yao ZJ, et al. Cancer stem cell-like side population cells in clear cell renal cell carcinoma cell line 769P. PLoS One. 2013;8:e68293. doi:10.1371/journal.pone.0068293

36. Hyun PW, Hee CY, Won JC, et al. Arsenic trioxide inhibits the growth of A498 renal cell carcinoma cells via cell cycle arrest or apoptosis. Biochem Biophys Res Commun. 2003;300:230-235.

37. Okada SL, Simmons RM, Franke-Welch S, et al. Conditioned media from the renal cell carcinoma cell line 786.0 drives human blood monocytes to a monocytic myeloid-derived suppressor cell phenotype. Cell Immunol. 2018;323:49-58. doi:10.1016/j.cellimm.2017.10.014

38. Wu Z, Zhao J, Qiu M, et al. CRISPR/Cas9 mediated GFP Knock-in at the MAP1LC3B locus in 293FT cells is better for bona fide monitoring cellular autophagy. Biotechnol J. 2018;13:e1700674. doi:10.1002/biot.201700674

39. Shi GH, Ye DW, Yao XD, et al. Involvement of microRNA-21 in mediating chemo-resistance to docetaxel in androgen-independent prostate cancer PC3 cells. Acta Pharmacol Sin. 2010;31:867-873. doi:10.1038/aps.2010.48

40. Guo Y, Wang J, Li H, et al. Mediator subunit 23 overexpression as a novel target for suppressing proliferation and tumorigenesis in hepatocellular carcinoma. $J$ Gastroenterol Hepatol. 2015;30:1094-1103. doi:10.1111/jgh.12923

41. Grada A, Otero-Vinas M, Prieto-Castrillo F, Obagi Z, Falanga V. Research techniques made simple: analysis of collective cell migration using the wound healing assay. J Invest Dermatol. 2017;137: e11-e16. doi:10.1016/j.jid.2016.11.020

42. Guo Y, Wang J, Zhang L, et al. Theranostical nanosystem-mediated identification of an oncogene and highly effective therapy in hepatocellular carcinoma. Hepatology. 2016;63:1240-1255. doi:10.1002/hep.28409

43. Prante BC, Garman KL, Sims BN, Lindsey JS. Matrix-coated transwell-cultured TM4 sertoli cell testosterone-regulated gene expression mimics in vivo expression. In Vitro Cell Dev Biol Anim. 2008;44:434-443. doi:10.1007/s11626-008-9135-8
44. Liu L, Wu J, Guo Y, et al. Overexpression of FoxM1 predicts poor prognosis of intrahepatic cholangiocarcinoma. Aging (Albany NY). 2018;10:4120-4140. doi:10.18632/aging. 101706

45. Betel D, Wilson M, Gabow A, Marks DS, Sander C. The microRNA. org resource: targets and expression. Nucleic Acids Res. 2008;36: D149-D153. doi:10.1093/nar/gkm995

46. Garcia DM, Baek D, Shin C, et al. Weak seed-pairing stability and high target-site abundance decrease the proficiency of 1sy-6 and other microRNAs. Nat Struct Mol Biol. 2011;18:1139-1146. doi:10.1038/ nsmb. 2115

47. Agarwal V, Bell GW, Nam JW, Bartel DP. Predicting effective microRNA target sites in mammalian mRNAs. Elife. 2015;4. doi:10.7554/eLife.05005.

48. Friedman RC, Farh KK, Burge CB, Bartel DP. Most mammalian mRNAs are conserved targets of microRNAs. Genome Res. 2009;19:92-105. doi:10.1101/gr.082701.108

49. Krek A, Grun D, Poy MN, et al. Combinatorial microRNA target predictions. Nat Genet. 2005;37:495-500. doi:10.1038/ng1536

50. Chen K, Rajewsky N. Natural selection on human microRNA binding sites inferred from SNP data. Nat Genet. 2006;38:1452-1456. doi: $10.1038 / \mathrm{ng} 1910$

51. Wang C, Guo Y, Wang J, Min Z. The suppressive role of SOX7 in hepatocarcinogenesis. PLoS One. 2014;9:e97433. doi:10.1371/journal.pone. 0097433

52. Zhang T, Liu W, Zeng XC, et al. Down-regulation of microRNA-338-3p promoted angiogenesis in hepatocellular carcinoma. Biomed Pharmacother. 2016;84:583-591. doi:10.1016/j.biopha.2016.09.056

53. Guo R, Wu Z, Wang J, et al. Development of a non-coding-RNAbased EMT/CSC inhibitory nanomedicine for in vivo treatment and monitoring of HCC. Adv Sci. 2019. doi:10.1002/advs.201801885

54. Jiao D, Chen J, Li Y, et al. miR-1-3p and miR-206 sensitizes HGF-induced gefitinib-resistant human lung cancer cells through inhibition of c-Met signalling and EMT. $J$ Cell Mol Med. 2018;22:3526-3536. doi:10.1111/jcmm.13629

55. Wang JY, Huang JC, Chen G, Wei DM. Expression level and potential target pathways of miR-1-3p in colorectal carcinoma based on 645 cases from 9 microarray datasets. Mol Med Rep. 2018;17:5013-5020. doi:10.3892/mmr.2018.8532

56. Gao L, Yan P, Guo FF, Liu HJ, Zhao ZF. MiR-1-3p inhibits cell proliferation and invasion by regulating BDNF-TrkB signaling pathway in bladder cancer. Neoplasma. 2018;65:89-96. doi:10.4149/ neo_2018_161128N594

57. Wang W, Shen F, Wang C, et al. MiR-1-3p inhibits the proliferation and invasion of bladder cancer cells by suppressing CCL2 expression. Tumour Biol. 2017;39:1393391281. doi:10.1177/1010428317698383

58. Liu W, Li H, Wang Y, et al. MiR-30b-5p functions as a tumor suppressor in cell proliferation, metastasis and epithelial-to-mesenchymal transition by targeting G-protein subunit alpha-13 in renal cell carcinoma. Gene. 2017;626:275-281. doi:10.1016/j.gene.2017.05.040

59. Yamasaki T, Seki N, Yamada Y, et al. Tumor suppressive microRNA138 contributes to cell migration and invasion through its targeting of vimentin in renal cell carcinoma. Int $J$ Oncol. 2012;41:805-817. doi:10.3892/ijo.2012.1543

60. Chaves KC, Turaca LT, Pesquero JB, et al. Fibronectin expression is decreased in metastatic renal cell carcinoma following endostatin gene therapy. Biomed Pharmacother. 2012;66:464-468. doi:10.1016/j.biopha.2012.04.003

61. Kondisetty S, Menon KN, Pooleri GK. Fibronectin protein expression in renal cell carcinoma in correlation with clinical stage of tumour. Biomark Res. 2018;6:23. doi:10.1186/s40364-018-0137-8

62. Knowles LM, Gurski LA, Engel C, et al. Integrin alphavbeta3 and fibronectin upregulate Slug in cancer cells to promote clot invasion and metastasis. Cancer Res. 2013;73:6175-6184. doi:10.1158/00085472.CAN-13-0602 
63. Bolos V, Peinado H, Perez-Moreno MA, et al. The transcription factor slug represses e-cadherin expression and induces epithelial to mesenchymal transitions: a comparison with snail and E47 repressors. J Cell Sci. 2003;116:499-511.

64. Sheng L, Zhang S, Xu H. Effect of slug-mediated down-regulation of E-cadherin on invasiveness and metastasis of anaplastic thyroid cancer cells. Med Sci Monit. 2017;23:138-143.

65. Wallesch M, Pachow D, Blucher C, et al. Altered expression of E-Cadherin-related transcription factors indicates partial epithelial-mesenchymal transition in aggressive meningiomas. J Neurol Sci. 2017;380:112-121. doi:10.1016/j.jns.2017.07.009

66. Li Z, Liu H, Zhong Q, Wu J, Tang Z. LncRNA UCA1 is necessary for TGF-beta-induced epithelial-mesenchymal transition and stemness via acting as a ceRNA for Slug in glioma cells. FEBS Open Bio. 2018;8:1855-1865. doi:10.1002/2211-5463.12533

67. Peng CY, Liao YW, Lu MY, et al. Downregulation of miR-1 enhances tumorigenicity and invasiveness in oral squamous cell carcinomas. JFormos Med Assoc. 2017;116:782-789. doi:10.1016/j.jfma.2016.12.003

68. Osaka E, Yang X, Shen JK, et al. MicroRNA-1 (miR-1) inhibits chordoma cell migration and invasion by targeting slug. J Orthop Res. 2014;32:1075-1082. doi:10.1002/jor.22632

69. Tominaga E, Yuasa K, Shimazaki S, Hijikata T. MicroRNA-1 targets Slug and endows lung cancer A549 cells with epithelial and anti-tumorigenic properties. Exp Cell Res. 2013;319:77-88. doi:10.1016/j.yexcr.2012.10.015
70. Liu YN, Yin JJ, Abou-Kheir W, et al. MiR-1 and miR-200 inhibit EMT via Slug-dependent and tumorigenesis via Slug-independent mechanisms. Oncogene. 2013;32:296-306. doi:10.1038/onc. 2012.58

71. Waalkes S, Atschekzei F, Kramer MW, et al. Fibronectin 1 mRNA expression correlates with advanced disease in renalcancer. BMC Cancer. 2010;10:503. doi:10.1186/1471-240710-503

72. Chen D, Gassenmaier M, Maruschke M, et al. Expression and prognostic significance of a comprehensive epithelial-mesenchymal transition gene set in renal cell carcinoma. J Urol. 2014;191:479-486. doi:10.1016/j.juro.2013.08.052

73. Steffens S, Schrader AJ, Vetter G, et al. Fibronectin 1 protein expression in clear cell renal cell carcinoma. Oncol Lett. 2012;3:787-790. doi:10.3892/ol.2012.566

74. Ma WW, Adjei AA. Novel agents on the horizon for cancer therapy. CA Cancer J Clin. 2009;59:111-137. doi:10.3322/caac.20003

75. Guo R, Wu Z, Wang J, et al. Development of a Non-Coding-RNAbased EMT/CSC Inhibitory Nanomedicine for In Vivo Treatment and Monitoring of HCC. Advanced Science. 2019; 6:1801885. doi:10.1002/advs.201801885

\section{Publish your work in this journal}

Cancer Management and Research is an international, peer-reviewed open access journal focusing on cancer research and the optimal use of preventative and integrated treatment interventions to achieve improved outcomes, enhanced survival and quality of life for the cancer patient
The manuscript management system is completely online and includes a very quick and fair peer-review system, which is all easy to use. Visit http://www.dovepress.com/testimonials.php to read real quotes from published authors. 